\title{
BMJ Open Mindfulness-based programme for residents: study protocol of a randomised controlled trial
}

\author{
Vanessa Marie-Jane Aeschbach (D) , 'Johannes Caspar Fendel (1) , \\ Anja Simone Göritz, ${ }^{2}$ Stefan Schmidt (i) ${ }^{1}$
}

To cite: Aeschbach VMJ, Fendel JC, Göritz AS, et al. Mindfulness-based programme for residents: study protocol of a randomised controlled trial. BMJ Open 2020;10:e035025. doi:10.1136/ bmjopen-2019-035025

- Prepublication history for this paper is available online. To view these files, please visit the journal online (http://dx.doi. org/10.1136/bmjopen-2019035025).

Received 17 October 2019 Revised 17 January 2020 Accepted 13 February 2020

A) Check for updates

(c) Author(s) (or their employer(s)) 2020. Re-use permitted under CC BY-NC. No commercial re-use. See rights and permissions. Published by BMJ.

${ }^{1}$ Department of Psychosomatic Medicine and Psychotherapy, Medical Center - University of Freiburg, Faculty of Medicine, Freiburg im Breisgau, Germany ${ }^{2}$ Department of Occupational and Consumer Psychology, Institute of Psychology, University of Freiburg, Freiburg im Breisgau, Germany

\section{Correspondence to}

Vanessa Marie-Jane Aeschbach; vanessa.aeschbach@uniklinikfreiburg.de

\section{ABSTRACT}

Introduction Residency is a stressful phase associated with high prevalence of mental distress. Besides impaired personal health, mental distress in residents has an impact on the quality of patient care and produces economic costs. Therefore, there is demand for interventions that improve resident physicians' mental health. The aim of the present study is to examine the effects of a mindfulnessbased intervention that has been tailored to residents' needs. Specifically, mindfulness has been supplemented by a focus on the concept of Muße.

Methods and analysis This study applies a randomised controlled multimethod design. Residents assigned to the intervention group will participate in an 8-week mindfulness course followed by a 4-month maintenance phase, whereas residents assigned to the control group will read text-based information about mindfulness on a weekly basis for the duration of 8 weeks. The intervention is focussed on a transfer of learnt techniques into the daily routine and is targeted to promote residents' self-care as well as on building empathic relationships. Participants will be assessed before, directly after the intervention, after the maintenance phase as well as at follow-up 6 months after the intervention group completes the intervention. Assessments will consist of self-report measures, physiological data, qualitative interviews, third-party reports as well as implicit and projective measures and will focus on both psychopathology and salutogenesis. The primary outcome will be burnout. Data will be analysed using linear mixed modelling.

Ethics and dissemination The study was approved by the ethics committee of the Medical Center University of Freiburg and is funded by the German Research Foundation as part of the interdisciplinary Collaborative Research Center 'SFB Muße 1015'. The results of this study will be published in scientific journals and disseminated through the study's website, and conferences.

Trial registration number DRKS00014015.

\section{INTRODUCTION}

Several studies show that hospitals are a challenging workplace as characterised by hierarchical structures, work density, time pressure, documentation duties and increasing focus on economic aspects. ${ }^{1-3}$ Within this system it is recognised that residency is an outstandingly

\section{Strengths and limitations of this study}

This study investigates a mindfulness-based intervention tailored to the particular needs and circumstances of resident physicians.

- The study investigates a long-term intervention (8week course, 4-month maintenance phase) using a longitudinal study design with four assessment points over the course of 1 year.

- We use a multimethod assessment including selfreports, physiological data, qualitative interviews, third-party reports as well as implicit and projective measures.

- If results are positive, this study will provide evidence for the effectiveness of an intervention through which residents can learn how to cope with stress and improve their mental well-being.

- The lack of a third group that receives standard mindfulness-based stress reduction (MBSR) will not allow for determining whether a mindfulness course tailored to residents' needs is superior to standard MBSR.

stressful phase due to long working hours combined with high workload, great responsibility, not feeling competent, lack of supervision, unclear hierarchies, lack of work-life balance and emotional strain. ${ }^{4-11}$

Accordingly, prevalence of mental distress is high in residents. Several large-scale studies report rates of burnout between $20 \%$ and $60 \%,{ }^{12-16}$ rates of depression between $20 \%$ and $50 \%^{13} 17$ and rates of anxiety between $30 \%$ and $40 \% .{ }^{17} 18$ Furthermore, residents with burnout have been shown to have increased rates of suicidality ${ }^{12}$ and substance abuse. ${ }^{19}$ However, stress at the workplace hospital and mental distress in physicians not only have consequences for residents themselves. That is, mental distress in physicians is associated with decreased patient safety and increased treatment errors. ${ }^{20-22}$ At the same time, stress is associated with decreased empathy and compassion ${ }^{2324}$ while empathy has been shown to be an important factor in 
treatment success and patient satisfaction. ${ }^{25}$ Furthermore, mental distress in physicians is associated with increased economic costs due to early retirement, reduced clinical hours and increased physician turnover. ${ }^{26-28}$ In sum, mental distress in residents comes at a price on residents' personal health, patient care as well as economic costs.

As a result, there is great demand for interventions that prevent mental distress and improve residents' well-being. Mindfulness-based interventions (MBI) are a promising approach to reduce mental distress and promote residents' well-being. Mindfulness is defined as a state of awareness that is characterised by focussing one's attention on the present moment with an attitude of openness and acceptance. ${ }^{29}$ A large body of literature demonstrates the beneficial effects of mindfulness interventions on reducing stress, depression and anxiety while increasing well-being and quality of life. ${ }^{30}$ Accordingly, several studies show similar results for MBIs in physicians. $^{32-38}$ In addition to improving physicians' mental health and well-being these studies also show that MBIs improve the quality of treatment. ${ }^{39-42}$ Consistent with these findings, preliminary studies reported beneficial effects of MBIs in residents. ${ }^{43-45}$ For instance, Rosdahl and others ${ }^{43}$ found that a single mindfulness session decreased perceived stress and burnout. Similarly, Lases and others ${ }^{44}$ and Ireland and others ${ }^{45}$ reported significant decreases in perceived stress and burnout after 5 or 10 sessions of mindfulness. However, by contrast Goldhagen and others, ${ }^{46}$ Verweij and others ${ }^{47}$ and Taylor and others ${ }^{48}$ did not find such an association. These initial studies are promising although inconclusive.

Residency represents a special stage within the professional career; therefore a MBI tailored to residents' needs may be more effective. In support of this, qualitative analyses by Lases and others ${ }^{44}$ indicated that residents who participated in a mindfulness course would have welcomed a tailoring of the programme to their needs. Furthermore, secular mindfulness interventions are increasingly being criticised for focussing too much on stress reduction, self-optimisation and improved performance rather than self-awareness and equanimity. ${ }^{49}$ Particularly within the context of clinical training that promotes self-sacrificing attitudes and performance orientation, ${ }^{50}$ mindfulness interventions are prone to be functionalised to further increase stress tolerance and performance. Consequently, there is a need for MBIs that emphasise a complementary state to daily stress and continuous performance orientation. Therefore, the aim of the present study is to investigate the effects of a MBI that has been tailored to residents' needs. To prevent the intervention from solely focussing on increasing performance and stress reduction, the main target of the intervention, that is, mindfulness, will be supplemented by a focus on $M u ß e$ within the present study. The term Muße is well introduced in the German language but cannot be directly translated into English. Muße refers to a state of serenity, equanimity, self-sufficiency and fulfilment in which one feels free of pressure. ${ }^{51} 52$ In other words, when experiencing Muße individuals feel at ease, content and free. By implementing a focus and goal on the experience of Muße as a state, the aim of the MBI is to enable participants-also at work-to access inner states that are beyond task-orientation, stress and time pressure. At a first glance, Muße and work may appear to contradict each other. However, being present in the moment and one's inner attitude are key to the experience of Muße regardless of context, and these qualities can be promoted through mindfulness practice. As a result of implementing a focus on Muße, the intervention aims at creating an opposite pole to stress and functioning.

In sum, the aim of this trial is to investigate a Mußedirected mindfulness intervention tailored to residents' needs consisting of an 8-week course followed by a 4-month maintenance phase. A randomised controlled design will be applied including quantitative, qualitative, implicit, projective, third-party, as well as physiological measures. The primary outcome is change in burnout from baseline to 6 months. The control group will receive a course book containing text-based information about mindfulness sent to participants on a weekly basis for the duration of 8 weeks. This will mimic the structure of the intervention group in terms of information and knowledge but not with respect to guided practice of mindfulness (ie, experience). We hypothesise that the mindfulness intervention compared with the control group will lead to (A) a reduction in psychopathological variables including burnout, perceived stress, depression and anxiety, and (B) will lead to an increase in positive aspects of mental health, including flourishing, satisfaction with life and self-compassion. Further, the aim of the qualitative analysis is to gain understanding of the effects of the MBI on participants' everyday life.

\section{METHOD \\ Design}

A randomised, controlled trial applying a mixedmethod approach will be conducted. Participants will be randomly assigned to either the intervention group receiving an 8-week mindfulness course followed by a 4-month maintenance phase or to the control group receiving a coursebook containing theoretical information about mindfulness for self-study. Assessments will be held at four time points: baseline ( $\mathrm{t} 0,0$ months), postintervention ( $\mathrm{t} 1,2$ months), after the maintenance phase (t2, 6 months) as well as 6 months after the end of the maintenance phase (t3, 12 months).

\section{Setting}

The study will be run in the south-west part of Germany. Residents will be recruited from a wide range of hospitals including university hospitals, hospitals in private sponsorship, hospitals in urban as well as rural areas. The courses of the mindfulness intervention will take place at the Medical Center of the University of Freiburg, 
Germany, while the control group will receive the selfstudy material about mindfulness via email.

\section{Participants}

To be included in the study, participants need to (1) be employed as resident at a hospital, (2) have a work contract with a minimum employment of $40 \%$, (3) have regular contacts with patients, (4) be less than 45 years old, (5) have sufficient German language skills and (6) have given informed consent. Exclusion criteria is not being willing to conform to study requirements.

\section{Recruitment, consent and allocation to interventions}

Residents will be recruited by approaching hospitals in south-west Germany and advertising the study to the employed residents, by email, intranet, informing head physicians about the study and by giving short presentations about the trial at the hospitals. Additionally, a webpage and flyers will inform about the trial. Interested residents may sign up using the registration form on the webpage or via email.

Before taking part in the study, residents will be provided with detailed information about the study in written form and will be given the opportunity to ask questions to a trained assessor. After consent has been obtained and the baseline assessment has been completed, participants will be assigned to either the intervention or the control group using a minimisation procedure for stratification. Stratification factors used for minimisation are gender and level of burnout (Copenhagen Burnout Inventory (CBI) values 1 to $2.5=$ low, 2.6 to $3.5=$ medium, 3.6 to $6.5=$ high burnout). The minimisation procedure applies a base probability of allocation of 0.8 and variance as distance measure. Minimisation will be carried out with the software QMinim. ${ }^{53}$ Allocation concealment will be ensured, as minimisation will take place after completion of all baseline assessments and will be carried out by a researcher who has no direct contact with participants. The flow of participants from recruitment to the end of the study is displayed in figure 1 .

\section{Intervention}

Mindfulness-based intervention: Residents allocated to this condition will take part in an 8-week course with weekly sessions lasting 2.5 hours each as well as a full day retreat (day of mindfulness, between Session 5 and 6), followed by a 4-month maintenance phase consisting of three monthly booster sessions lasting 2.5 hours each. Additionally, participants are encouraged to practice at home by completing homework over the course of the 8 -week intervention. The courses will be organised in groups of 6 to 14 participants and will be led by three physicians who are certified mindfulness-based stress reduction (MBSR) and mindfulness-based cognitive therapy (MBCT) teachers with extensive experience in teaching mindfulness classes.

The mindfulness intervention is based on the original manual of MBSR by John Kabat-Zinn, ${ }^{54}$ has been

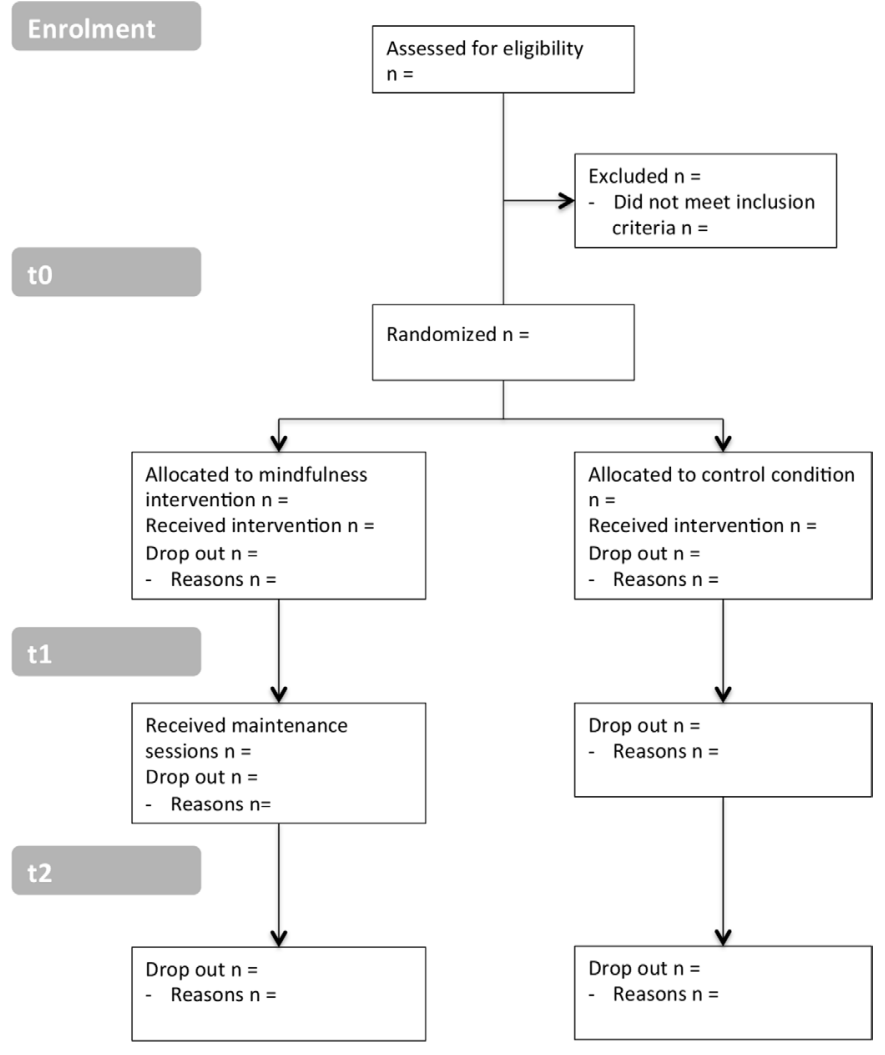

t3

Figure 1 Planned flow of participants.

tailored to residents' needs and given a focus on Muße. To tailor the programme, we conducted an a priori needs assessment consisting of an in-depth literature search (ie, residency specific stressors, ${ }^{4-11}$ character traits that are more prevalent in residents, ${ }^{55}{ }^{56}$ content and culture of medical training ${ }^{50}$ ) as well as a set of interviews with residents (ie, asking about residency specific stressors and how they experience their work environment). The specific customisation addressed four aspects: First, we identified and integrated resident specific topics such as mindful communication with patients or dealing with stressors of residency (ie, high responsibility while not feeling competent enough, lack of supervision, unclear hierarchies or high workload, fear of making mistakes, etc). This also includes the capability to establish an empathic and compassionate relationship with patients despite time pressure. Table 1 gives an overview of the topics covered during the course. Second, a result of the literature search was that within the context of medical education, a MBI might run the danger of solely being used for self-optimisation and to function better under stress. Therefore, mindfulness is supplemented by a focus on $M u \beta e$ that is incompatible with self-optimisation. The word Muße is well established in the German language. Thus, the aim is to activate the cognitive concept of Muße and create an association between states of Muße and practicing mindfulness meditation. Specifically, every course session is completed by a discussion on the 


\begin{tabular}{|c|c|c|}
\hline Session & Topic & Content \\
\hline 1 & Mindfulness & $\begin{array}{l}\text { Exploring residents' needs and expectations; introducing mindfulness as a mode of being, } \\
\text { as contrasted to a mode of doing and performing during everyday life. }\end{array}$ \\
\hline 2 & $\begin{array}{l}\text { Dealing with barriers } \\
\text { and subjective time } \\
\text { perception }\end{array}$ & $\begin{array}{l}\text { Discussing ways to deal with barriers to mindfulness practice; exploring mindfulness } \\
\text { anchors in daily routine (eg, mindful walking along hospital corridors; mindful stop before } \\
\text { entering a patient's room; mindful hand disinfection); introducing mindfulness to experience } \\
\text { slower passage of time and to mitigate the feeling of time pressure. }\end{array}$ \\
\hline 3 & Dis-identification & $\begin{array}{l}\text { Coping with painful emotions, thoughts and physical sensations; raising awareness of } \\
\text { the process of constructing reality through ones experiences; connecting with the inner- } \\
\text { observer and exploring dis-identification to learn to non-identify with the self and to reduce } \\
\text { reactivity towards them. }\end{array}$ \\
\hline 4 & Stress & $\begin{array}{l}\text { Discussing resident specific stressors; psychoeducation on physiological and psychological } \\
\text { processes of stress; exploring how to cope with stress using mindfulness. }\end{array}$ \\
\hline & Day of Mindfulness & $\begin{array}{l}\text { All-day silent retreat. Practicing mindfulness intensively; reinforcing mindfulness as a } \\
\text { reliable tool in both everyday life and daily medical practice. }\end{array}$ \\
\hline 6 & $\begin{array}{l}\text { Mindfulness in patient } \\
\text { contact }\end{array}$ & $\begin{array}{l}\text { Using mindfulness in therapeutic interactions; building a compassionate communication } \\
\text { atmosphere with patients, even in moments of time pressure. Learning to listen mindfully } \\
\text { and exploring the benefits of letting patients complete voicing their agenda of concerns. }\end{array}$ \\
\hline 7 & Self-care & $\begin{array}{l}\text { Discussing why self-care is especially relevant to resident physicians and its connection to } \\
\text { quality of care; exploring ways to take care of oneself in daily routine. }\end{array}$ \\
\hline 8 & $\begin{array}{l}\text { Enhancing meaning in } \\
\text { work and mindfulness } \\
\text { as part of life }\end{array}$ & $\begin{array}{l}\text { Exploring what is meaningful in professional life and how meaning can be enhanced. } \\
\text { Reinforcing mindfulness as part of everyday life and daily medical practice. }\end{array}$ \\
\hline
\end{tabular}

experience of Muße and participants are encouraged to practice mindfulness in a spirit of Muße. A third adaptation is the inclusion of a large number of transfer exercises with the aim of enabling participants to get into a state of mindful awareness during everyday life (informal practice) and not only during formal meditation practice. Example of such transfer exercises are, feeling one's feet while walking down the hospital corridor, feeling one's body during regular hand disinfection or taking a short break observing one's breath before entering a patient's room. Fourth, additional information and scientific background to course elements is given to residents. Such an approach complies with the recommendations of the American Medical Association, British Medical Association and Canadian Medical Association for mindfulness interventions addressing physicians. ${ }^{57}$

On the structural level, every course session consists of five elements: (1) an educational input, (2) mindfulness exercises (ie, sitting meditation, body scan, mindful yoga or mindful walking), (3) a reflection of one's practice, (4) transfer exercises such as role plays or group exercises and (5) home assignments.

The maintenance phase consists of threemonthly booster sessions of 2.5 hours each during which exercises learnt and topics treated in the course are refreshed. Additionally, the sessions of the maintenance phase allow for space for participants to reflect and discuss their experiences and difficulties in practicing and applying mindfulness in their work context as well as in everyday life.

Control group: Residents assigned to the control group will receive a coursebook on mindfulness containing the same written material about mindfulness practice and the respective background that participants of the intervention group will receive. This text-based material consists of a detailed description and definition of mindfulness, studies on mindfulness, stress, coping with stress, acceptance, self-care and meaning in medicine as well as inspiring stories and poems about mindfulness. The chapters of the coursebook will be sent to participants on a weekly basis via email for the duration of 8 weeks, in parallel to the mindfulness course. By this choice of control group, we can compare experience-based learning with text-based learning.

\section{Outcome measures}

The aim of the present study is to investigate the effects of the adapted mindfulness intervention on both stress and associated pathology and positive mental health. The primary outcome (ie, burnout) as well as secondary outcomes will be assessed at four points of time: at baseline ( $\mathrm{t} 0,0$ months), after the intervention ( $\mathrm{t} 1,2$ months), after the maintenance phase (t2, 6 months), as well as 6 months after completion of the maintenance phase (t3, 12 months). Assessment methods used include standardised self-report questionnaires, implicit tests, 
projective tests, physiological and behavioural markers, qualitative measures and third-party reports. Additionally, at baseline, demographics will be assessed as well as participants' previous experience with meditation. Similarly, at t3, major life events that might influence the results will be assessed as well as participants' sick leave days over the past year.

\section{Primary outcome}

The primary outcome is change in burnout between t0 and $\mathrm{t} 2$, and it will be assessed using the German version of the CBI. ${ }^{58}{ }^{59}$ The CBI is a 19-item self-report questionnaire that yields three subscales for personal burnout, work-related burnout and client-related burnout. Participants will rate to what extent they experience certain symptoms such as feeling tired or exhausted on a 5-point Likert scale from 0 (never/rarely) to 100 (very often). The CBI has been shown to have high internal consistency with a Cronbach's alpha between 0.85 and $0.87 .^{589}$

\section{Secondary outcomes}

Self-report questionnaires

We differentiate between measures pertaining to psychopathology and measures pertaining to salutogenesis as well as additional variables including errors at work, selfreported mindfulness, physician empathy and perception of time.

The measures pertaining to psychopathology include perceived stress, psychopathology and mental distress, job strain, depression and anxiety. Perceived stress will be assessed by the German version of the Perceived Stress Scale (PSS) ${ }^{6061}$ The PSS consists of 10 items that require participants to rate how often they experienced certain aspects of stress during the preceding month using a 5-point Likert scale from 0 (never) to 4 (very often). The scale has been shown to have good internal consistency with a Cronbach's alpha of 0.83 to $0.86 .{ }^{6061}$

Psychopathology and mental distress will be assessed using the German version of the General Health Questionnaire (GHQ-12) ${ }^{62}{ }^{63}$ an instrument commonly used as a screening instrument for psychological disorders. Participants rate how often they experienced certain symptoms such as being able to concentrate or thinking of oneself as worthless during the past weeks on a 4-point Likert scale from 0 (not at all) to 3 (much more than usual). The GHQ-12 has been shown to gave good internal consistency with a Cronbach's aplha of $0.91 .^{63}$

Depression and anxiety will be assessed with the German translation of the Patient Health Questionnaire (PHQ-4) that consists of four screening items for depression and anxiety. ${ }^{64}$ Participants will rate how often they experienced certain symptoms over the past 2 weeks on a 4-point Likert scale from 0 (not at all) to 3 (almost every day). Both the PHQ-4 and the GHQ-12 have been shown to have high validity and internal consistency with a Cronbach's alpha between 0.86 and $0.91^{62} 63$ and between 0.82 and $0.85 .^{6465}$
Job strain will be measured using the German version of the Irritation Questionnaire. ${ }^{66}$ This scale asks participants to rate eight statements about emotional and cognitive strain on a 7-point Likert scale from 1 (not at all) to 7 (very much). Internal consistency has been shown to be good with a Cronbach's alpha between 0.85 and $0.93{ }^{66}$

Secondary outcomes focussing on positive mental health (ie, salutogenesis) include well-being, selfcompassion, self-esteem, self-efficacy as well as the feeling of being loved. Well-being comprises both hedonic and eudaimonic aspects. ${ }^{67}$ Hedonic aspects include positive affect and satisfaction with life. Positive affect will be assessed using the Self-Assessment Manikin (SAM) ${ }^{68}$ The SAM requires participants to indicate their emotional state via five abstract faces depicting a semantic differential from negative (frowning face, coded as 1 ) to positive emotions (happy face, coded as 5).

Satisfaction with life will be assessed with the one item short scale $\mathrm{L}-1^{69}$ that asks participants to give a global rating of how satisfied they are with their life on an 11-point Likert scale from 0 (not satisfied at all) to 10 (absolutely satisfied). The L-1 has been shown to have good testretest reliability as well as high convergent validity with other, multi-item scales that measure satisfaction with life. $^{69}$

Eudaimonic well-being can be defined as positive functioning in daily life ${ }^{70}$ and will be assessed using the German translation of the Flourishing Scale (FS).$^{70} 71$ The FS requires participants to rate eight statements about the experience of certain aspects of well-being in their lives on a 7-point Likert scale ranging from 7 (strongly agree) to 1 (strongly disagree). The FS has been shown to have good internal consistency with a Cronbach's alpha between 0.86 and $0.87 .^{7071}$

Well-being specifically related to the job will be assessed with the German translation of the Thriving at Work Scale $(\mathrm{TS})^{72}$ that measures positive functioning at the workplace. The TS consists of ten statements that are rated on a 5-point Likert scale from 1 (not true at all) to 5 (absolutely true) and has been shown to have good internal consistency with a Cronbach's alpha between 0.90 and $0.93 .{ }^{72}$

Job satisfaction (ie, a person's cognitive and affective evaluations of their work) will be assessed by the Faces Scale. ${ }^{73}$ This scale consists of seven abstract faces representing a semantic differential from negative (frowning face, coded as 1) to positive (happy face, coded as 7).

Self-compassion can be defined as being kind and understanding towards oneself $\mathrm{f}^{74}$ and will be measured with the German translation of the short form of the SelfCompassion Scale (SCS). ${ }^{75} 76$ The short form of the SCS consists of 12 statements that are rated on a 5-point Likert scale from 1 (almost never) to 5 (almost always). The scale has been shown to have a good internal consistency with a Cronbach's alpha of $0.86 .^{75}$

Global self-esteem will be measured with the SingleItem Self-Esteem Scale (SISE), ${ }^{77}$ consisting of rating one statement ('I have high self-esteem') on a 5-point scale from 1 (not very true for me) to 5 (very true for me). A 
validation study demonstrated good test-retest reliability and good convergent validity with other longer measures of self-esteem. ${ }^{67}$ The SISE has been translated to German by the authors.

Self-efficacy or the belief in one's ability to succeed will be assessed using the Self-Efficacy Questionnaire. ${ }^{78}$ This self-report scale consists of three items that are scored on a 5-point Likert scale from 1 (not true at all) to 5 (very true). The scale has good internal consistency with a McDonald's omega of $0.81 .^{68}$

The feeling of being loved by others and the feeling of loving oneself will be assessed with the Feeling Loved Questionnaire. ${ }^{79}$ This questionnaire consists of one Yes/No question (ie, 'Do you feel loved?') followed by an item assessing the continuous rating (ie, 'How loved do you feel?') for both dimensions. The scale has good convergent and discriminant validity. ${ }^{79}$ The feeling loved questionnaire was translated to German by the authors.

Self-reported mindfulness will be assessed using the Freiburg Mindfulness Inventory (FMI) ${ }^{80}$ The FMI is a self-report instrument consisting of 14 statements about specific aspects of mindfulness experienced in everyday life. Participants indicate how often they experienced these aspects during the past week on a 4-point Likert scale from 0 (rarely) to 3 (almost always). The questionnaire has good internal consistency with a Cronbach's alpha of $0.86 .^{80}$

Subjective perception of time will be measured by an abridged version of the Time Perception Questionnaire ${ }^{81}$ that requires participants to rate statements about how time is perceived on a 5-point Likert scale from strongly disagree to strongly agree. To generate an abridged version, the author of the original questionnaire selected five items, which he considered to be the most relevant.

Physician empathy refers to the ability of understanding the patient's perspective and being able to communicate this. Physician empathy will be assessed using a shortened version of the Jefferson Scale of Physician Empathy. ${ }^{8283}$ The original scale consists of 20 statements that are answered on a 7-point scale from 1 (strongly disagree) to 7 (strongly agree). However, in the present study we chose six items that have been shown to have the highest factor loadings in two validation studies with $193^{82}$ and $704^{84}$ physicians, respectively. We used the German translation mentioned in. $^{83}$

The experience of Muße will be measured using a selfconstructed questionnaire. ${ }^{85}$ We believe that like satisfaction with life, ${ }^{69} \mathrm{Muße}$ is a state that is directly accessible and can thus be measured by directly asking participants about respective experiences. Thus, in a first step, participants will indicate how often they experienced Muße during the past 4 weeks. Answers are given on a 6-point Likert scale from never to very often. In a second step, participants will report how often they experienced Muße within specific situations (ie, at work, in their leisure time, at home, away from their home, when being alone, during quiet situations, when being in action) during the past 4 weeks.
Answers are given on the same 6-point Likert scale as in the first part.

Errors at work are assessed with a self-report questionnaire that distinguishes two types of errors: errors due to lack of experience and errors due to lack of time. ${ }^{86}$ Participants will indicate how often certain errors had occurred giving their ratings on a 5-point Likert scale from 1 (never occurs) to 5 (occurs often). The questionnaire has satisfactory internal consistency with a Cronbach's alpha between 0.62 and 0.64 for each subscale. ${ }^{86}$ The six questions were translated into German by the authors.

\section{Physiological and behavioural outcome measures}

In addition to self-report measures, stress will be assessed by measuring participants' cortisol level from a hair sample. The advantage of measuring cortisol in a hair sample compared with blood or saliva is that it provides an aggregated long-term measure. Specifically, a hair sample of $1 \mathrm{~cm}$ length and $3 \mathrm{~mm}$ in diameter will be taken close to the posterior vertex. This allows for evaluating the cumulative cortisol level of approximately the last 4 weeks. ${ }^{87}$ The hair samples will be sent to the laboratory of Professor Dr Kirschbaum at the Technical University of Dresden, Germany, to determine the level of cortisol.

Moreover, affect and stress will be assessed on a behavioural level by recording participants' mouse movement and keyboard use in the online questionnaire. This exploratory measure is based on preliminary results supporting the rationale that emotional states influence sensorimotor and cognitive processes causing measurable changes in our interaction with computer input devices such as the keyboard and mouse usage. ${ }^{88} 89$

Keyboard and mouse usage behaviour will be captured by participants' web browser using a JavaScript script embedded in the online questionnaire. The script will track the mouse cursor's $\mathrm{x} / \mathrm{y}$ coordinates on the screen as well as each keyboard key press and key release at millisecond precision.

\section{Implicit measures}

In contrast to measuring attitude and emotional state using self-report questionnaires, implicit measures do not require introspection and thus provide a different level of tapping the effects of the intervention. ${ }^{90}$

Attitude towards the job will be assessed using the single category implicit association test (SC-IAT). In the SC-IAT, words are displayed in the centre of the screen one at a time together with categorising words for 'positive' and 'negative' as well as the category 'job as physician' on the sides of the screen. Participants need to categorise the words that appear in the centre of the screen. In one block the categorising labels for 'positive' and 'job as physician' share one key and in a second block labels for 'negative' and 'job as physician' share a key. Reaction times will be recorded. Shorter reaction times when 'job as physician' is paired with positive in contrast to when it is paired with negative indicate a positive attitude towards the job ${ }^{91}$ and vice versa. 
Furthermore, attitude towards the job will be assessed using the affect misattribution procedure (AMP). In the AMP, participants are presented with briefly appearing pictorial primes referring to the job as physician followed by neutral Chinese pictograms. Participants are instructed to rate how visually pleasant the Chinese pictograms are, giving their responses as fast as possible. ${ }^{92}$ It is assumed that the ratings of the Chinese pictograms reflect participants' attitude towards their job as physician. ${ }^{92}$

\section{Projective measures}

Similar to implicit measures, projective tests do not require introspection. Emotional state will be assessed with the Implicit Positive and Negative Affect Test (IPANAT). In the IPANAT participants are presented with six artificial non-sense words (SAFME, VIKES, TUNBA, TALEP, BELNI and SUKOV) and are asked to rate to what extent these words express positive emotional states (happy, cheerful and energetic) and negative emotional states (tense, inhibited and helpless). ${ }^{93}$ The positivity or negativity of the ratings reflects participants trait affect. ${ }^{93}$

Additionally, emotional state will be assessed by the word fragment test (WFT). The WFT requires participants to complete a series of word fragments. These fragments are constructed in a way that they can be completed into at least two words that are either associated with positive or negative affect. For example, the word fragment 'ange_' can be completed into 'angel' or 'anger'. ${ }^{90}$ This test is based on the assumption that depending on the current affective state, either positive or negative words are more accessible and are thus more likely to be generated. Consequently, the proportion of positive and negative words that are generated by participants allows for inferring their affect. ${ }^{90}$

Self-esteem will be assessed using the name-liking task. The name-liking task $^{94}$ is a single-item measure that requires participants to rate how much they like their full name. The name-liking task has been derived from the mere ownership effect according to which objects related to and representing the self are evaluated more positively. It is assumed that these evaluations are influenced by one's self-esteem unconsciously resulting in a relationship between rating of objects representing the self, such as one's name and self-esteem. The name-liking task has been translated to German by the authors.

\section{Qualitative measures}

Complementing self-report questionnaires, cortisol, implicit and projective assessments we will implement qualitative assessments.

Goal attainment scaling: Goal attainment scaling (GAS) refers to the evaluation of an outcome based on personalised goals set by participants themselves. GAS allows for evaluating an intervention by taking account of the personal relevance of an outcome, which is not commonly the case for standardised measurements. ${ }^{95}$ At baseline, participants will be asked to describe the main goal they aspire in taking part in an 8-week mindfulness course.
After the intervention, participants will be presented with their goal and will be asked to rate in how far they have achieved that goal. Participants will answer on a 5-point scale from -2 (much less than expected) to 2 (much more than expected) with 0 (as expected).

Interviews: Semi-structured interviews will be held with a subgroup of participants of both groups between the end of the intervention and the first follow-up assessment. The interview will follow a semi-structured guideline consisting of open-ended questions that address particular topics described below. Participants will be encouraged to talk about these topics freely, followed by more specific questions addressing certain aspects of interest. These topics include general motivation for participating in a mindfulness course, how they experienced the course/reading material, observed effects of the course/ reading material, aspects of the course/reading material they found beneficial/not beneficial and what Muße means to them. The interviews will be audio recorded for later transcription. For the purpose of triangulation a single open-ended question that asks about the effects of participation in the study on participants' life will be included in the questionnaire at $\mathrm{t} 2$ after the maintenance phase and will be answered by all participants.

\section{Third-party reports}

In addition to self-reports collected from participants directly we will include third-party reports. At t0 (baseline) as well as at t2 (after the maintenance phase), a supervisor, a colleague, as well as three patients will be asked to complete a short questionnaire about the respective resident. This questionnaire requires respondents to rate statements about how tense, empathic and present the resident appears. Ratings are given on a 7-point Likert scale ranging from 0 (not at all) to 6 (very much). Respondents will be selected by the residents, that is, residents will give the questionnaires to the respondents. To ensure that third-party reports are anonymous, questionnaires have previously been labelled with the residents' anonymous code and will be sent to the researchers in a prepaid envelope.

\section{Adherence}

We document participants' course attendance as well as their daily mindfulness practice for the duration of the 8-week course via a self-constructed sheet. Participants that will have attended at least five out of nine mindfulness classes will be defined as completers and will be included in the final analysis.

\section{Fidelity of implementation}

Quality of the mindfulness intervention will be ensured through certified MBSR and MBCT teachers with extensive experience in practicing mindfulness and teaching mindfulness classes. The mindfulness teachers are physicians themselves, having a profound understanding of the situation residents find themselves in. Furthermore, adherence to the manual was ensured through detailed 
descriptions of the course sessions in the instructor's guide. Moreover, treatment fidelity will be assessed by videotaping two random course sessions that will be rated by two independent raters using the Mindfulness-Based Interventions Teaching Assessment Criteria. ${ }^{97}$

\section{Procedure}

Residents will enrol for the study by email or via the study's webpage. Eligible residents will be invited to a first on-site appointment, where they will receive further information about the study and will be asked to give their informed consent. After baseline assessment, participants will be assigned to one of the two groups using the minimisation procedure described above. Participants will receive educational points for participating in the mindfulness course but no other incentives will be given. Participants will be invited to take part in the assessments via email. Assessment at each measurement point consists of an online questionnaire ${ }^{98}$ as well as an on-site appointment. The on-site appointment consists of the collection of the hair sample and the GAS at $\mathrm{t} 0$ and $\mathrm{t} 1$, while the online questionnaire contains the self-report questionnaires, the implicit and projective tests as well as the recording of mouse and key use. Furthermore, participants of the first three courses and respective control group (ie, 84 residents) will be invited to take part in a qualitative interview, which will also be held on-site. Theoretical sampling is not possible because this study is fully anonymised, meaning that we are unable to link the names of participants to their identifying code and data. However, retrospectively we will be able to determine whether the subsample of residents that took part in the interviews covers a range of typical attributes that are of interest from a theoretical perspective such as experienced stress level and experienced effect of the intervention. Together with the criteria of theoretical saturation, this will determine whether we will invite additional participants to the interview or not. To promote participant retention for the follow-up assessments, participants will be contacted and reminded by email to take part in the assessments.

\section{Procedures to reduce bias}

Due to the nature of the study, neither the participants nor the trainers running the mindfulness courses can be completely blinded. However, to minimise bias, the selfreport questionnaires as well as the implicit assessments will be conducted using an online survey. Furthermore, all on-site assessments (ie, taking the hair samples) that are carried out after participants have been assigned to a group will be conducted by assessors that will be blind to group allocation. Additionally, participants will be asked not to tell the assessor which group they have been allocated to. An exception to this procedure will be the qualitative interviews that are held with a subsample of participants, and will be carried out by a researcher who will not carry out other assessments.

\section{Data protection}

Regarding data protection, all data will be stored under an anonymous code that can be linked to data only by the participants themselves. An exception to this is the short interval between baseline assessment and allocation to group during which a temporary list linking name and anonymous code will be maintained, which allows for communicating to participants to which group they have been allocated. After allocation has taken place, this temporary list will be destroyed.

The hair samples will be sent to a laboratory in Dresden, Germany, (Technical University Dresden, Germany) that will destroy the hair samples after the cortisol level has been obtained.

There will be no formal data monitoring committee since there is no known risk for the intervention and the trial includes no patients. To ensure quality of data, all data that have not been collected via the online survey will undergo a double data entry.

\section{Calculation of sample size}

Previous studies that applied a similar design found effects of a mindfulness intervention on mental health variables of around $d=0.45 .^{30} 31$ Accordingly, to find a significant group difference at $\mathrm{t} 2$, assuming a power of 1-beta $=0.80$ and an alpha level of 0.05 (one-tailed) the sample size would have to be at least 62 participants per group. Adding customary drop-out rate of 30 per cent results in a planned sample of 89 participants per group or 178 participants in total. Estimation of sample size was conducted using the software G*Power. ${ }^{99}$ For the purpose of sample size calculation we used a simple group comparison; however, in the actual analysis we will use a linear mixed model, which by nature has higher power.

\section{Planned analysis \\ Quantitative data}

The analyses will be conducted on an intention-totreat principle. The primary outcome will be analysed using linear mixed modelling comparing the respective outcome measure between participants of the intervention group and participants of the control group. Participants will be analysed as randomised. In case of drop-out and non-adherence, this subgroup's baseline values in the primary outcome will be compared with the other participants. We expect that these groups do not differ significantly. Furthermore, the pattern of missing values will be analysed. By conducting linear mixed models, missing data will be dealt with by using maximum likelihood to obtain estimates of missing parameters.

Effects of the intervention will be examined by looking at the interaction of time and group by entering group as fixed factor and assuming a random intercept within the linear mixed model. Additionally, time will be entered as a random effect, that is, allowing for random slopes if this would improve model fit. The hierarchical structure of the data due to the organisation of participants into different courses, taught by different teachers will be 
taken into account by specifying course as a separate level. Similar models will be calculated for secondary outcomes.

\section{Qualitative data}

Audio recordings of the interviews will be transcribed applying the transcription method by Dresing and Pehl. ${ }^{100}$ These transcripts will be analysed using thematic analysis, following the six-step process proposed by Braun and Clarke. ${ }^{101}$ In a first step, we will familiarise ourselves with the material by repeatedly reading the transcripts to gain an understanding of the scope and depth of the interviews. In a second step, initial codes will be generated by identifying meaningful groups within the interview data. In a third step, the generated codes will be organised into overarching themes. In a fourth step, these themes will be reviewed by reassessing whether the themes adequately represent the codes and the data as a whole. In a fifth step, the identified themes will be labelled and described in detail with the aim of capturing the essence of each theme. The sixth and last step consists of the final analysis, choosing of representative text excerpts and writing down the results. Steps one to five will each be done individually by two researchers, followed by a comparison and discussion of the results in groups with at least three researchers. Data transcription, processing and analysis will be carried out using the software MAXQDA. ${ }^{102}$

\section{Patient and public involvement}

The intervention aims at improving resident physicians' mental health and does not address patients directly. However, there is evidence that physicians' mental health fosters the quality of care they deliver. Thus, there may be an indirect benefit for patients. Furthermore, patients are involved in the study directly within the third party reports. Specifically, three patients of every resident will be asked to complete a short questionnaire about the respective resident.

There is a study webpage informing the public about the study.

\section{Ethics approval}

The planned study was approved by the Institutional Ethics Committee of the Albert-Ludwigs University of Freiburg (Reference number: 361/16) and is funded by the German Research Foundation as part of the interdisciplinary collaborative research center 'SFB Muße 1015'. The trial was registered at the German Clinical Trials Register of Clinical Studies (drks.de). The collection of data started in September 2018. Changes to the study protocol will be reported to the ethics committee and will be updated in the trial registry of the DRKS. Only participants that have given their written informed consent will be included in the study.

\section{Dissemination plans}

The results of this study will be published in scientific journals and disseminated through the study's website. Further, participants will receive the results of the hair cortisol analysis after completion of the final assessment at t3.

\section{DISCUSSION}

Residents show high prevalence of mental distress including burnout, perceived stress, depression, and anxiety. ${ }^{12-18}$ This comes at a price of both inferior patient treatment and increased economic costs. That is why there is a need for interventions that address this problem. The aim of the present work is to examine the effects of a mindfulness intervention that has been tailored to residents' needs. If results are positive, this study will demonstrate evidence of an intervention through which residents can learn how to cope with stress and improve their mental health. This could further imply that such programmes should become an integral part of occupational health management models in hospitals since there is a lack of programmes in which residents can learn such competencies. Dealing with stressors at work, distress, time pressure and the downsides of economy-driven healthcare systems are crucial competences that have not been part of the formal curriculum so far.

However, such a MBI may run the risk of being functionalised to make residents more stress-resistant in order to engage in either more self-sacrificing or self-optimising behaviour at work. By supplementing mindfulness with a focus on Muße, we aim to make mindfulness practice a counter-pole to stress and functioning that addresses the mental health of residents. The integration of the concept of Muße into the MBI follows a recently emerging line of second-generation MBIs that are characterised by the combination of mindfulness with other principles such as ethical awareness or compassion. ${ }^{103104}$

The present study will have several limitations. First, the lack of a third group that receives standard MBSR will not allow for determining whether a mindfulness course tailored to residents' needs is superior to a standard mindfulness programme. Therefore, if this trial is successful, further studies should include such a comparison in their design. Second, the control group will receive text-based information about mindfulness. It is intended that participants allocated to this group will read on a weekly basis for the duration of 8 weeks, paralleling the structure of the intervention group in terms of information. However, we are not able to control for whether the material will actually be read and comprehended with the same intensity than in the course. Third, participants will be a selfselected sample of residents instead of a random sample. Yet, the strength of this study is its ecological validity by assessing the effectiveness of the mindfulness intervention in those residents who actually seek such an intervention. Furthermore, the likely effects of such an intervention depend on the motivation of the participants and such an intervention cannot be administered passively like in a drug trial. Fourth, external evaluations might be biassed because residents may tend to give the questionnaires to patients where treatment was successful and colleagues 
and supervisors where the relationship is positive. However, this does not present a threat to internal validity as this practice will be present in both the intervention and the control group. Fifth, the mindfulness courses will be held at one hospital only, which might limit the generalisability of the results to this specific context. However, residents will be recruited from a wide range of hospitals including university hospitals, clinics in private as well as public ownership, church-funded hospitals, as well as hospitals in both urban and rural areas. As a result, we expect a diverse sample that generalises to the hospital landscape in Germany. Last, a part of the measurements will consist of self-report scales that are known to be susceptible to participants' expectation of intervention effects, vagueness in evaluating their mental state and/or social desirability. For this reasons, self-report scales are supplemented by other means of assessment that are less susceptible to these pitfalls including hair cortisol and implicit measurements.

Acknowledgements The authors thank Susanne Bregulla-Kuhn, Klaus Kuhn and Marc Loewer, who were involved in the tailoring of the mindfulness intervention to residents (the manual of the intervention will be published separately).

Contributors SS and ASG developed the initial study concept and obtained funding. All authors contributed to the design of the study and were involved in the development of the adapted mindfulness intervention. VMA drafted the study protocol while JCF, ASG and SS made important revisions. All authors have read and approved the manuscript.

Funding The planned study is funded by the German Research Foundation (Deutsche Forschungsgemeinschaft, DFG), grant number 197396619 - SFB 1015 and is part of the Collaborative Research Centre SFB 1015 Muße. The article processing charge was funded by the Baden-Wuerttemberg Ministry of Science, Research and Art and the Albert Ludwigs University Freiburg in the funding programme Open Access Publishing.

Competing interests None declared.

Patient consent for publication Not required.

Provenance and peer review Not commissioned; externally peer reviewed.

Open access This is an open access article distributed in accordance with the Creative Commons Attribution Non Commercial (CC BY-NC 4.0) license, which permits others to distribute, remix, adapt, build upon this work non-commercially, and license their derivative works on different terms, provided the original work is properly cited, appropriate credit is given, any changes made indicated, and the use is non-commercial. See: http://creativecommons.org/licenses/by-nc/4.0/.

ORCID iDs

Vanessa Marie-Jane Aeschbach http://orcid.org/0000-0002-0217-9687

Johannes Caspar Fendel http://orcid.org/0000-0002-3852-5422

Stefan Schmidt http://orcid.org/0000-0003-4858-4220

\section{REFERENCES}

1 Albrecht C, Giernalczyk T. Ärzte im Krankenhaus. Psychother Im Dialog 2016;17:36-9.

2 Angerer P, Petru R, Nowak D, et al. Arbeitsbedingungen und Depression bei Ärzten. Dtsch med Wochenschr 2008;133:26-9.

3 Zwack J, Bodenstein U, Mundle G, et al. Pathogenetische und salutogenetische Aspekte der Ärztegesundheit - eine qualitative Katamnese betroffener Ärzte. Psychiatr Prax 2012;39:181-8.

4 Beerheide R. Deutsches Ärzteblatt: Junge Ärzte hadern mit Klinikalltag.pdf. Dtsch Ärzteb/ 2017;114:399-400.

5 Brennan N, Corrigan O, Allard J, et al. The transition from medical student to junior doctor: today's experiences of Tomorrow's Doctors. Med Educ 2010;44:449-58.

6 Buddeberg-Fischer B, Klaghofer R, Buddeberg C. Arbeitsstress und gesundheitliches Wohlbefinden junger Ärztinnen und Ärzte/ stress at work and well-being in junior residents. Z Für Psychosom Med Psychother 2005;51:163-78.

7 Buddeberg-Fischer B, Dietz C, Klaghofer R, et al. Swiss residents arguments for and against a career in medicine. BMC Health Serv Res 2006:6-9.

8 Buddeberg-Fischer B, Stamm M, Buddeberg C, et al. Chronic stress experience in young physicians: impact of person- and workplacerelated factors. Int Arch Occup Environ Health 2010;83:373-9.

9 Prins JT, Gazendam-Donofrio SM, Tubben BJ, et al. Burnout in medical residents: a review. Med Educ 2007;41:788-800.

10 Raspe M, Müller-Marbach A, Schneider M, et al. Arbeits- und Weiterbildungsbedingungen deutscher Assistenzärztinnen und -ärzte in internistischer Weiterbildung. DMW - Dtsch Med Wochenschr 2016;141:202-10.

11 Raspe M, Vogelgesang A, Fendel J, et al. Arbeits- und Weiterbildungsbedingungen deutscher Assistenzärztinnen und -ärzte in internistischer Weiterbildung: Eine zweite bundesweite Befragung durch die Nachwuchsgruppen von DGIM und BDI. DMW-Deutsche Medizinische Wochenschrift 2018;143:42-50.

12 van der Heijden F, Dillingh G, Bakker A, et al. Suicidal thoughts among medical residents with burnout. Arch Suicide Res 2008;12:344-6.

13 Dyrbye LN, West CP, Satele D, et al. Burnout among U.S. medical students, residents, and early career physicians relative to the general U.S. population. Acad Med 2014;89:443-51.

14 West CP, Shanafelt TD, Kolars JC. Quality of life, burnout, educational debt, and medical knowledge among internal medicine residents. JAMA 2011;306:952-60.

15 Lebares CC, Guvva EV, Ascher NL, et al. Burnout and stress among US surgery residents: psychological distress and resilience. J Am Coll Surg 2018;226:80-90.

16 Kemper KJ, McClafferty H, Wilson PM, et al. Consortium, on behalf of the P. R. B.-R. S. do mindfulness and self-compassion predict burnout in pediatric residents? Academic Medicine 2018;94:876-84.

17 Pereira-Lima K, Loureiro SR. Burnout, anxiety, depression, and social skills in medical residents. Psychol Health Med 2015;20:353-62.

18 Kerrien M, Pougnet R, Garlantézec R, et al. Prévalences des troubles anxieux, de l'humeur et de la souffrance au travail des internes de médecine. La Presse Médicale 2015;44:e84-91.

19 Lebensohn P, Dodds S, Benn R, et al. Resident wellness behaviors. Fam Med 2013;45:541-9.

20 Fahrenkopf AM, Sectish TC, Barger LK, et al. Rates of medication errors among depressed and burnt out residents: prospective cohort study. BMJ 2008;336:488-91.

21 Williams ES, Manwell LB, Konrad TR, et al. The relationship of organizational culture, stress, satisfaction, and burnout with physician-reported error and suboptimal patient care: results from the MEMO study 2007;32:203-12.

22 Shanafelt TD, Balch CM, Bechamps G, et al. Burnout and medical errors among American surgeons. Ann Surg 2010;251:995-1000.

23 Darley JM, Batson CD. "From Jerusalem to Jericho": A study of situational and dispositional variables in helping behavior. J Pers Soc Psychol 1973;27:100-8.

24 Babineau T, Thomas A, Wu V. Physician burnout and compassion fatigue: individual and institutional response to an emerging crisis. Curr Treat Options Pediatr 2019;5:1-10.

25 Kelm Z, Womer J, Walter JK, et al. Interventions to cultivate physician empathy: a systematic review. BMC Med Educ 2014;14:219-29.

26 Dewa CS, Jacobs P, Thanh NX, et al. An estimate of the cost of burnout on early retirement and reduction in clinical hours of practicing physicians in Canada. BMC Health Serv Res 2014;14:9.

27 Tziner A, Rabenu E, Radomski R, et al. Work stress and turnover intentions among hospital physicians: the mediating role of burnout and work satisfaction. Rev Psicol Trab Las Organ 2015;31:207-13.

28 Moreno-Jiménez B, Gálvez-Herrer M, Rodríguez-Carvajal R, et al. A study of physicians' intention to quit: the role of burnout, commitment and difficult doctor-patient interactions. Psicothema 2012;24:263-70.

29 Kabat-Zinn J. Mindfulness-Based interventions in context: past, present, and future. Clinical Psychol Sci Prac 2003;10:144-56.

30 Sedlmeier P, Eberth J, Schwarz M, et al. The psychological effects of meditation: a meta-analysis. Psychol Bull 2012;138:1139-71.

31 Khoury B, Sharma M, Rush SE, et al. Mindfulness-based stress reduction for healthy individuals: a meta-analysis. J Psychosom Res 2015;78:519-28.

32 Burton A, Burgess C, Dean S, et al. How effective are MindfulnessBased interventions for reducing stress among healthcare 
professionals? A systematic review and meta-analysis. Stress Health 2017:33:3-13.

33 Fortney L, Luchterhand C, Zakletskaia L, et al. Abbreviated mindfulness intervention for job satisfaction, quality of life, and compassion in primary care clinicians: a pilot study. Ann Fam Med 2013;11:412-20.

34 Hamilton-West K, Pellatt-Higgins T, Pillai N. Does a modified mindfulness-based cognitive therapy (MBCT) course have the potential to reduce stress and burnout in NHS GPs? feasibility study. Prim Health Care Res Dev 2018;19:591-7.

35 Verweij H, Waumans RC, Smeijers D, et al. Mindfulness-based stress reduction for GPs: results of a controlled mixed methods pilot study in Dutch primary care. Br J Gen Pract 2016;66:e99-105.

36 Amutio A, Martínez-Taboada C, Hermosilla D, et al. Enhancing relaxation states and positive emotions in physicians through a mindfulness training program: a one-year study. Psychol Health Med 2015;20:720-31

37 West CP, Dyrbye LN, Erwin PJ, et al. Interventions to prevent and reduce physician burnout: a systematic review and meta-analysis The Lancet 2016;388:2272-81.

38 Panagioti M, Panagopoulou E, Bower P, et al. Controlled interventions to reduce burnout in physicians: a systematic review and meta-analysis. JAMA Intern Med 2017;177:195-205.

39 Epstein R. Mindful practice: a key to patient safety. Focus Patient Saf 2011;14:3-7.

40 Krasner MS, Epstein RM, Beckman H, et al. Association of an educational program in mindful communication with burnout, empathy, and attitudes among primary care physicians. JAMA 2009;302:1284-93.

41 Beckman HB, Wendland M, Mooney C, et al. The impact of a program in mindful communication on primary care physicians. Acad Med 2012;87:815-9.

42 Amutio-Kareaga A, García-Campayo J, Delgado L, et al. Improving communication between physicians and their patients through mindfulness and compassion-based strategies: a narrative review. JCM 2017;6:33-17.

43 Rosdahl JA, Kingsolver K. Mindfulness training to increase resilience and decrease stress and burnout in ophthalmology residents: a pilot study. ARVO Journals 2014;55

44 Lases SS, Lombarts MJMH, Slootweg IA, et al. Evaluating mind fitness training and its potential effects on surgical residents' wellbeing: a mixed methods pilot study. World J Surg 2016;40:29-37.

45 Ireland MJ, Clough B, Gill K, et al. A randomized controlled trial of mindfulness to reduce stress and burnout among intern medical practitioners. Med Teach 2017;39:409-14.

46 Goldhagen BE, Kingsolver K, Stinnett SS, et al. Stress and burnout in residents: impact of mindfulness-based resilience training. Adv Med Educ Pract 2015;6:525-32.

47 Verweij $\mathrm{H}$, van Ravesteijn $\mathrm{H}$, van Hooff MLM, et al. MindfulnessBased stress reduction for residents: a randomized controlled trial. J Gen Intern Med 2018;33:429-36.

48 Taylor M, Hageman JR, Brown M. A mindfulness intervention for residents: relevance for pediatricians. Pediatr Ann 2016;45:e373-6.

49 Harrington A, Dunne JD. When mindfulness is therapy: ethical qualms, historical perspectives. Am Psychol 2015;70:621-31.

50 Miller NM, McGowen RK. The painful truth: physicians are not invincible. South Med J 2000;93:966-73.

51 Figal G. Muße als Forschungsgegenstand. Muße Ein Mag 2015;1:17-25.

52 Gouda S, Luong MT, Schmidt S, et al. Students and teachers benefit from Mindfulness-Based stress reduction in a schoolembedded pilot study. Front Psychol 2016;7:18.

53 Saghaei M, Saghaei S. Implementation of an open-source customizable minimization program for allocation of patients to parallel groups in clinical trials. J Biomed Sci Eng 2011;04:734-9.

54 Kabat-Zinn J. Full catastrophe living: using the wisdom of your body and mind to face stress, pain, and illness. New York: Delacourt: Random House LLC, 1990.

55 Wallace JE, Lemaire JB, Ghali WA. Physician wellness: a missing quality indicator. The Lancet 2009;374:1714-21.

56 Miller NM, McGowen RK. The painful truth: physicians are not invincible. South Med J 2000;93:966-73.

57 Dobkin PL, Hickman S, Monshat K. Holding the heart of mindfulness-based stress reduction: balancing fidelity and imagination when adapting MBSR. Mindfulness 2014:5:710-8.

58 Kristensen TS, Borritz M, Villadsen E, et al. The Copenhagen burnout inventory: a new tool for the assessment of burnout. Work Stress 2005;19:192-207.

59 Hanebuth D, Aydin D, Scherf T. Burnout and related conditions in managers: a five-year longitudinal study. Psychol Everyday Act 2012;5:4-39.
60 Cohen S, Kamarck T, Mermelstein R. A global measure of perceived stress. J Health Soc Behav 1983:24:385-96.

61 Klein EM, Brähler E, Dreier M, et al. The German version of the perceived stress scale - psychometric characteristics in a representative German community sample. BMC Psychiatry 2016;16:10

62 Goldberg DP, Blackwell B. Psychiatric illness in general practice: a detailed study using a new method of case identification. $B M J$ 1970;2:439-43.

63 Schrnitz N, Kruse J, Tress W. Psychometric properties of the general health questionnaire (GHQ-12) in a German primary care sample. Acta Psychiatr Scand 1999;100:462-8.

64 Kroenke K, Spitzer RL, Williams JBW, et al. An ultra-brief screening scale for anxiety and depression: the PHQ-4. Psychosomatics 2009;50:613-21.

65 Löwe B, Wahl I, Rose M, et al. A 4-item measure of depression and anxiety: validation and standardization of the patient health questionnaire-4 (PHQ-4) in the general population. J Affect Disord 2010;122:86-95.

66 Mohr G, Rigotti T, Müller A. Irritation - ein Instrument zur Erfassung psychischer Beanspruchung im Arbeitskontext. Skalen- und Itemparameter aus 15 Studien. Z Für Arb- Organ AO 2005;49:44-8.

67 Ryan RM, Deci EL. On happiness and human potentials: a review of research on hedonic and eudaimonic well-being. Annu Rev Psychol 2001;52:141-66.

68 Bradley MM, Lang PJ. Measuring emotion: the self-assessment manikin and the semantic differential. J Behav Ther Exp Psychiatry 1994:25:49-59.

69 Beierlein C, Kovaleva A. Kurzskala zur Erfassung der allgemeinen Lebenszufriedenheit (L-1). Zusammenstellung Sozialwissenschaftlicher Items Skalen 2015;19.

70 Diener E, Wirtz D, Biswas-Diener R, et al. New measures of wellbeing. In: Diener E, ed. Assessing well-being. Dordrecht: Springer Netherlands, 2009: 247-66.

71 Esch T, Jose G, Gimpel C, et al. Die Flourishing scale (FS) von Diener et al. liegt jetzt in einer autorisierten deutschen Fassung (FSD) vor: Einsatz bei einer mind-body-medizinischen Fragestellung. Forsch Komplementmed 2013;20:267-75.

72 Porath C, Spreitzer G, Gibson C, et al. Thriving at work: toward its measurement, construct validation, and theoretical refinement. $J$ Organ Behav 2012;33:250-75.

73 Kunin T. The construction of a new type of attitude measure. Pers Psychol 1955;8:65-77.

74 Neff KD. Self-Compassion, self-esteem, and well-being. Soc Personal Psychol Compass 2011;5:12

75 Raes F, Pommier E, Neff KD, et al. Construction and factorial validation of a short form of the self-compassion scale. Clin Psychol Psychother 2011;18:250-5

76 Hupfeld J, Ruffieux N. Validierung einer deutschen Version der SelfCompassion Scale (SCS-D). Zeitschrift für Klinische Psychologie und Psychotherapie 2011;40:115-23.

77 Robins RW, Hendin HM, Trzesniewski KH. Measuring global self-esteem: construct validation of a single-item measure and the Rosenberg self-esteem scale. Pers Soc Psychol Bull 2001:27:151-61.

78 Beierlein C, Kovaleva A, Kemper C, et al. Allgemeine Selbstwirksamkeit Kurzskala (ASKU). Zusammenstellung Sozialwissenschaftlicher Items Skalen 2014;14.

79 Barrett B, Muller D, Hayer S, et al. Feeling loved: a novel brief selfreport health measure. EXPLORE 2019;15:148-59.

80 Walach $\mathrm{H}$, Buchheld N, Buttenmüller V, et al. Measuring mindfulness - the Freiburg mindfulness inventory (FMI). Pers Individ Dif 2006;40:1543-55.

81 Jokic T, Zakay D, Wittmann M. Individual differences in selfrated impulsivity modulate the estimation of time in a real waiting situation. Timing Time Percept 2018;6:71-89.

82 Hojat M, Mangione S, Nasca TJ, et al. The Jefferson scale of physician empathy: development and preliminary psychometric data. Educ Psychol Meas 2001;61:349-65.

83 Doering S, Schneider G, Burgmer M, et al. Evaluation des Praktikums "Psychosomatik und Psychotherapie« mit standardisierten Patienten. Z Für Psychosom Med Psychother 2010;56:385-98.

84 Hojat M, Gonnella JS, Nasca TJ, et al. Physician empathy: definition, components, measurement, and relationship to gender and specialty. Am J Psychiatry 2002;159:1563-9.

85 Heger B. Muße als psychologisches Konstrukt. Eine theoretische und empirische Annäherung Unpublished Thesis.

86 Prins JT, van der Heijden FMMA, Hoekstra-Weebers JEHM, et al. Burnout, engagement and resident physicians' self-reported errors. Psychol Health Med 2009;14:654-66. 
87 Kirschbaum C, Tietze A, Skoluda N, et al. Hair as a retrospective calendar of cortisol production-Increased cortisol incorporation into hair in the third trimester of pregnancy. Psychoneuroendocrinology 2009;34:32-7.

88 Zimmermann P, Guttormsen S, Danuser B, et al. Affective computing--a rationale for measuring mood with mouse and keyboard. Int J Occup Saf Ergon 2003;9:539-51.

89 Yamauchi T, Xiao K. Reading emotion from mouse cursor motions: affective computing approach. Cogn Sci 2018;42:771-819.

90 Uhlmann EL, Leavitt K, Menges Jl, et al. Getting explicit about the implicit: a taxonomy of implicit measures and guide for their use in organizational research. Organ Res Methods 2012;15:553-601.

91 Karpinski A, Steinman RB. The single category implicit association test as a measure of implicit social cognition. J Pers Soc Psychol 2006;91:16-32.

92 Payne BK, Cheng CM, Govorun O, et al. An inkblot for attitudes: affect misattribution as implicit measurement. J Pers Soc Psychol 2005;89:277-93.

93 Quirin M, Kazén M, Kuhl J. When nonsense sounds happy or helpless: the implicit positive and negative affect test (IPANAT). J Pers Soc Psychol 2009;97:500-16.

94 Gebauer JE, Riketta M, Broemer P, et al. "How much do you like your name?" An implicit measure of global self-esteem. J Exp Soc Psychol 2008;44:1346-54.

95 Cox R, Amsters D. Goal attainment scaling: an effective outcome measure for rural and remote health services. Aust $J$ Rural Health 2002;10:256-61.
96 Kiresuk T, Smith A, Cardillo J. Goal attainment scaling: applications, theory, and measurement. Psychol Press 2014;42:1974-83.

97 Crane RS, Soulsby JG, Kuyken W, et al. The Universities of Bangor, Exeter \& Oxford Mindfulness-Based Interventions: Teaching Assessment Criteria (MBI-TAC) manual, summary and addendum. 201698 Unipark EFS Survey. Cologne, Germany: Questback $\mathrm{GmbH}, 2016$.

99 Questback GmbH. Unipark EFS survey. Cologne, Germany: Questback GmbH, 2019.

99 Faul F, Erdfelder E, Lang A-G, et al. G*Power 3: a flexible statistical power analysis program for the social, behavioral, and biomedical sciences. Behav Res Methods 2007;39:175-91.

101 Dresing T, Pehl T. Praxisbuch Interview, Transkription \& Analyse. In: Anleitungen und Regelsysteme für qualitativ Forschende. 8th edn. Marburg: dresing und pehl GMBH, 2018.

101 Braun V, Clarke V. Using thematic analysis in psychology. Qual Res Psychol 2006;3:77-101.

102 VERBY. MAXQDA Analytics Pro. Berlin: Germany: VERBY, 2016.

103 Van Gordon W, Shonin E, Griffiths MD. Towards a second generation of mindfulness-based interventions. Aust $N Z J$ Psychiatry 2015;49:591-2.

104 Singh NN, Lancioni GE, Winton ASW, et al. Mindfulness-based positive behavior support (MBPBS) for mothers of adolescents with autism spectrum disorder: Effects on adolescents' behavior and parental stress. Mindfulness 2014;5:646-57. 